\title{
BIM FRAMEWORK: VARIABLES FOR THEORY AND IMPLEMENTATION
}

\author{
Youngsoo Jung \\ Myongji University, Yongin 449-728, South Korea \\ yjung97@mju.ac.kr \\ Mihee Joo \\ Myongji University, Yongin 449-728, South Korea \\ within17@hanmail.net
}

\begin{abstract}
Recent advances in building information modelling (BIM) have disseminated the utilization of three-dimensional (3D) graphic information in the construction industry. Nevertheless, overall and practical effectiveness of BIM utilization is difficult to justify at this stage. The purpose of this paper is to propose a BIM framework focusing on the issues of practicability for real-world projects. Even though previous efforts in the BIM framework has properly addressed the BIM variables, comprehensive issues in terms of BIM effectiveness need to be further developed. A thorough literature review of computer-integrated construction (CIC) and BIM was performed first in order to interpret the BIM in a global perspective. A comprehensive BIM framework is then developed to address the variables for theory and implementation. This framework can provide a basis for evaluating promising areas and identifying driving factors for practical BIM effectiveness.
\end{abstract}

KEYWORDS: CIC, BIM, framework, variables, practicability

\section{INTRODUCTION}

Utilizing information systems (IS) in the construction industry has been an issue of great importance in order to enhance the effectiveness of construction projects throughout the life cycle and across the business functions. However, the concept of information systems (IS) in construction is very broad and subjective (Jung and Gibson 1999). Formulating comprehensive frameworks of IS in construction, therefore, would effectively facilitate strategic utilization of IS.

Computer integrated construction (CIC) and building information modelling (BIM) are the most often used acronyms representing the broad concept of IS in construction. Nevertheless, there have been limited efforts in systematically defining these concepts for theory and implementation. In this context, the purpose of this paper is to provide a comprehensive framework of BIM in order to evaluate promising areas and identify driving factors for practical applications in real world construction projects. 


\section{CIC AND BIM: RECIPROCAL CONVERGENCE}

In an attempt to develop an IS planning methodology prioritizing construction business value chains, Jung and Gibson (1999) defined CIC as "the integration of corporate strategy, management, computer systems, and information technology throughout the project's entire life cycle and across different business functions". In this definition, managerial issues including 'corporate strategy' and 'management' were strongly stressed utilizing several analytical methods for effective implementation of CIC concepts. One of the sub-issues for CIC was the integration between graphical data and non-graphical data among fourteen different construction business functions (Sanvido and Medeiros 1990; Teicholz and Fisher 1994; Jung and Gibson 1999).

\section{Top-Down: Curtailment in CIC Scopes}

CIC efforts in 1990's generally tried to incorporate entire graphic data and non-graphic data throughout an organization or a project. A Japanese CIC project exploited a full scale, on-site automation combining information and robotics all through design, procurement, and construction (Miyatake and Kangari 1993). Another research funded by Korean government developed fully integrated CIC systems using two real-world projects (Jung and Gibson 1998; Cho 2000). It is inferred that these two CIC projects were successful in terms of technical capability and holistic approach, however, practical effectiveness were not proven to be economically feasible. Even at this moment, it is still hard to justify the cost-benefits of these systems. Lessons learned from early CIC implementations indicate that the multidimensional (nD) integration is hard to achieve, and partial integration based on priorities makes the CIC implementation more viable (Jung and Gibson 1998a; Jung and Gibson 1999).

\section{Bottom-Up: Expansion in BIM Applications}

Recent BIM proliferation has represented a reverse approach to achieve the integration. BIM has started to fully utilize 3D graphic data first, and then expands the usage into an $\mathrm{nD}$ environment. It is encouraging that this expansion is getting towards more construction business functions and engineering analyses. Several researchers have investigated practical effectiveness of BIM too. Koo and Fisher (2004) explored the issues for 4D-CAD systems in terms of effectiveness and practicability. Expanding the usage of BIM was also investigated by Taylor and Bernstein (2009) focusing on the patterns such as "visualization, coordination, analysis, and supply chain integration”. A comprehensive BIM perspective was recently proposed by Succar (2009) addressing a full range of IS concerns as discussed in CIC.

\section{CIC and BIM Convergence for Practical Effectiveness}

It is notable that different approaches in CIC and BIM would be suitable depending on the distinct characteristics of an organization or a project. For some projects, fully integrated CIC implementation may effectively support the successful project management (Jung and Gibson 1998b). However, in general, this reciprocal convergence of CIC and BIM implies the needs and issues of optimizing mechanisms for IS in construction. The BIM framework proposed in this paper is to provide a basis to this optimization. Variables are explored and organized focusing on BIM issues while encompassing CIC concerns. 


\section{BIM VARIABLES}

The BIM framework in this paper proposes a hierarchical structure with twelve variables classified within four major categories. These four major categories include 'property', 'relation', 'standards', and 'utilization' as shown in Figure 1 and Figure 2. Note that the variables are attempted to be fully independent each other in the framework in order to facilitate further analyses and applications.

\section{Property}

'Property' variables in this study represent the characteristics of BIM objects or data.

Most often discussed issue in this variable is the 'parametric' property of data, namely 'geometric (graphic)' or 'non-geometric (non-graphic)' properties. Geographic data generally refer to design or engineering drawings. However, graphic representations in this framework are defined to include any non-drawing objects such as working envelopes or trajectories due to the fact that these geometric objects are frequently used to enhance the BIM practicability.

The 'level' of BIM data or any construction data can be classified as 'raw data', 'information', and 'knowledge' in an incremental order in terms of property intelligence and accumulation.

The categorization of 'facets' for construction information is well defined by standard classifications such as ISO (1994), Uniclass (1997), and MasterFormat (2004). For the purpose of simplified and effective BIM application in construction, this study adapts the definitions of 'locator' and 'commodity' by Jung and Kang (2007) as the facet variable. Locator indicates the physical breakdown including facility, space, element facets while commodity handles the work items or materials (e.g. Main building $1^{\text {st }}$ floor concrete work). The concept of 'locator' and 'commodity' facilitates to easily retrieve, analyse, and accumulate BIM raw data with rich information and knowledge (Jung and Kang 2007).

\section{Relation}

'Relation' is defined as a physical or logical interdependency between 'properties'.

First variable in 'relation' category is the 'composition' which composes or decomposes the 'properties'. The concepts of 'link', 'group', and 'layer' constitute the 'composition' variable. 'Link' refers to the interconnection between different 'properties' (Kymmell 2008; Wender 2009). 'Groups' and 'layers' are basically composing the objects. However, these objects can belong to more than one 'groups' while they cannot belong to more than one 'layer'.

'Ontology' in this study focuses on physical interdependency between object 'properties' while 'reasoning' depicts logical interdependency between them. 'Objects' can have structural and physical 'hierarchies' with 'semantic' interpretations.

In a research exploring the "use of qualitative geometric reasoner for integrated design", Chinowsky and Reinschmidt (1995) thoroughly defined 'reasoning' as "temporal, logical, or spatial interrelationship". Their research provided an opportunity to automate 3D design process by linking the objects with integrated knowledge-based reasoning. It is noteworthy that they positively elaborated utilizing of knowledge for graphic objects. 


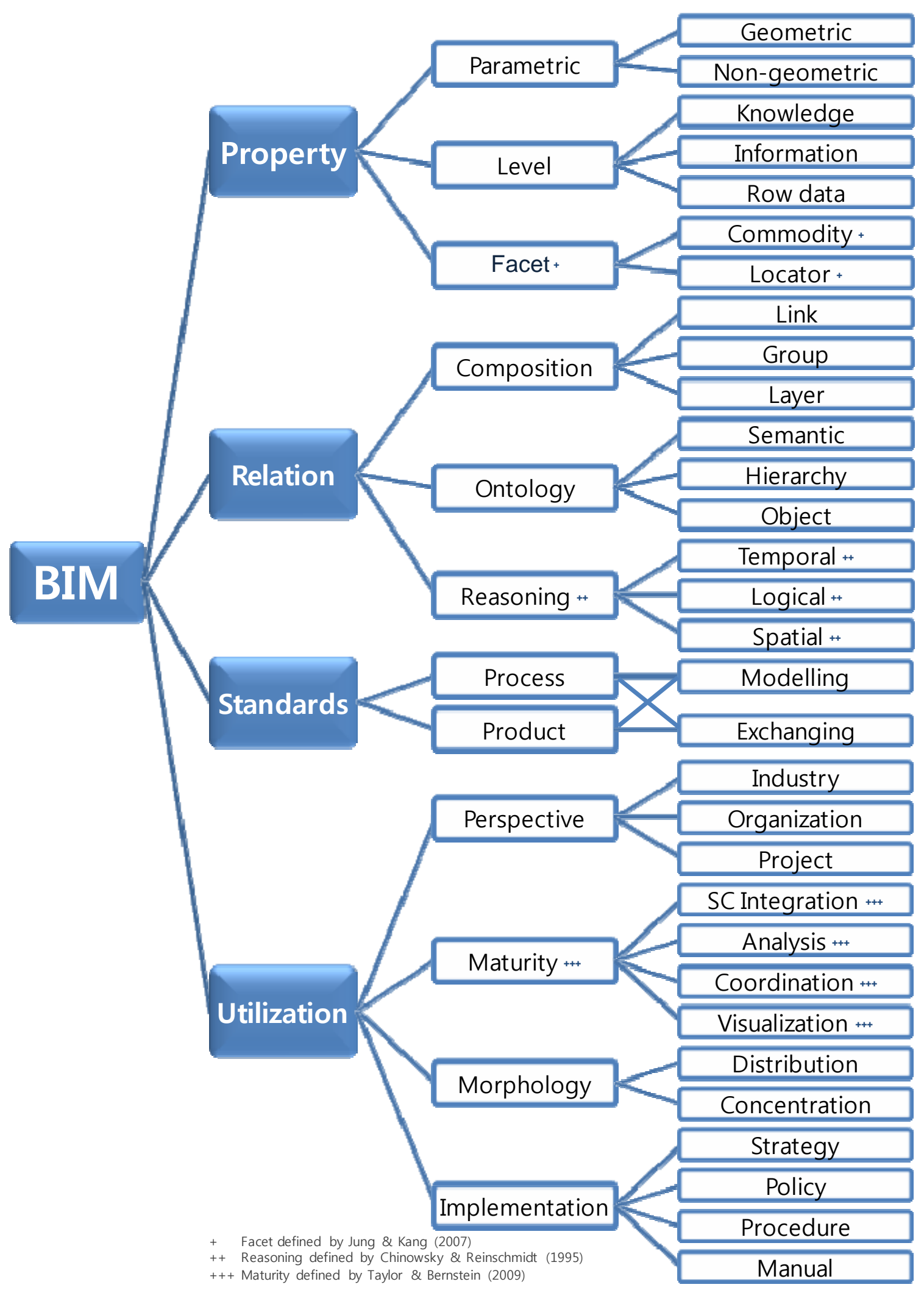

Figure 1: BIM Framework 


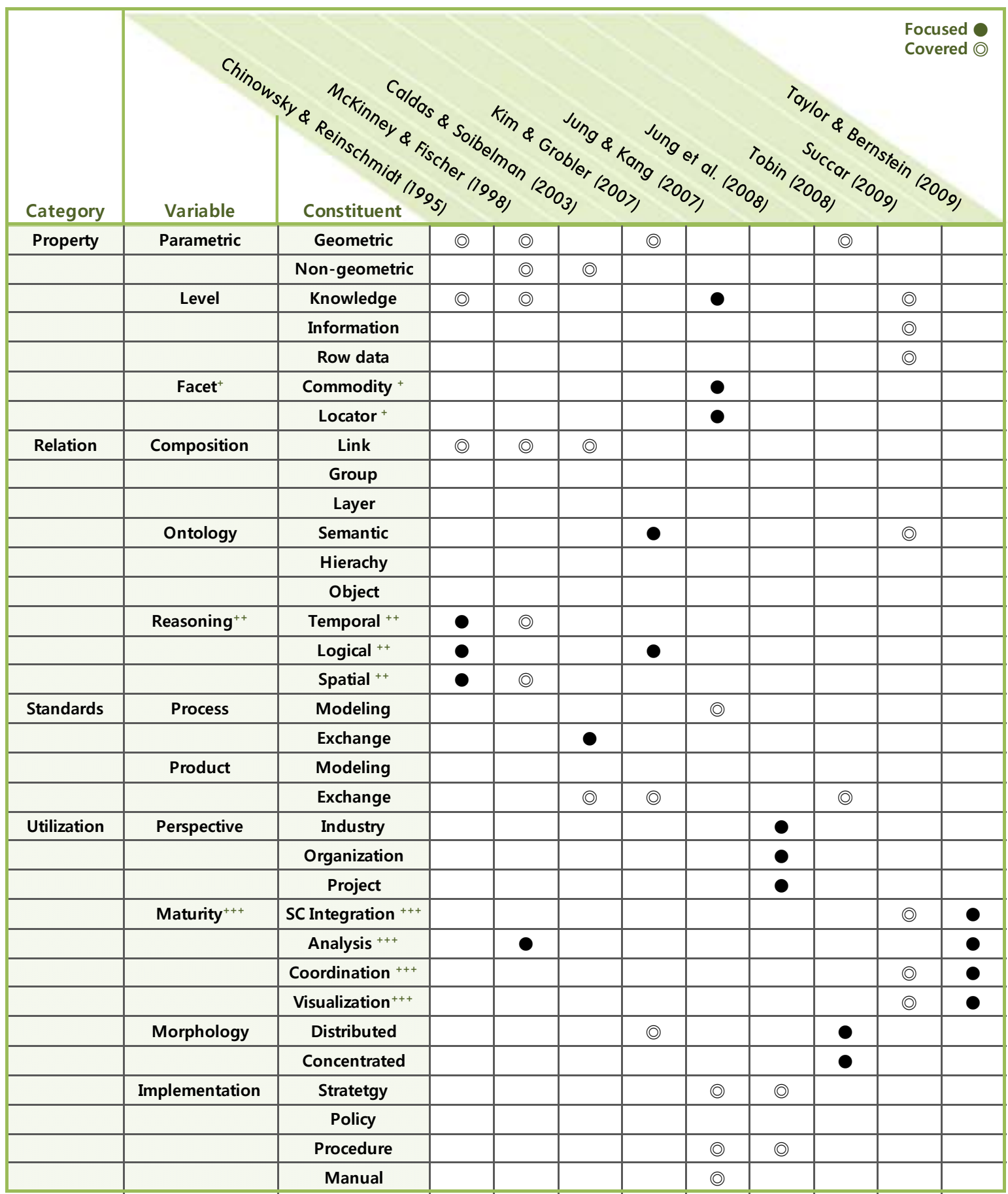

$+\quad$ Facet defined by Jung $\&$ Kang (2007)

++ Reasoning defined by Chinowsky \& Reinschmidt (1995)

+++ Maturity defined by Taylor \& Bernstein (2009)

Figure 2: BIM Variables for Theory and Implementation 


\section{Standards}

Issues of BIM 'standards' and interoperability have been widely addressed by many researchers and practitioners (Taylor and Bernstein 2009). Rigorous efforts including Industry Foundation Classes (IFC) and Information Delivery Manual (IDM) by several international organizations also developed the details.

Variables within 'standards' category can be classified into two constituents, the 'process' and 'product' standards. Literature in this issue has generally focused on the 'product' standards perspective for 'modelling' and 'exchanging' (Caldas and Soibelman 2003; Kim and Grobler 2007; Tobin 2008). Caldas and Soibelman (2003) exerted the active use of 'process' standards for construction documentations. Integrated 'process' and 'product' modelling has also been investigated by utilizing different approaches (Jung and Gibson 1998a; Cho 2000; Bouchlaghem et al. 2004).

Nevertheless, the 'standards' variables in this study is basically stressing the intensity of utilizing standards. Another important issue for standardization is the level of perspective where the standards are designed and utilized. Jung and Kang (2007) illustrated the different needs and issues for standards making depending on different level of perspectives.

\section{Utilization}

The major purpose of proposed framework is to identify promising areas and driving factors for enhancing practical BIM effectiveness. 'Utilization' variables consist of 'perspectives', 'maturity', 'morphology', and ‘implementation'.

As described in Jung and Kang (2007), the 'perspective' (e.g. industry, organization, or projects) characterizes distinct information systems requirements. Well defined 'implementation' strategies and polices are crucial for successful BIM utilization (Jung and Gibson 1999).

In their study examining BIM practice paradigms, Taylor and Bernstein (2009) explained four phases of BIM advancement; "visualization, coordination, analysis, and supply chain (SC) integration". "BIM experience" and "electronic file sharing" were tested as the affecting factors for this evolving advancement. 'Maturity' in this paper adapts these four paradigms defined by Taylor and Bernstein (2009). As for advanced 4D-CAD systems, McKinney and Fischer (1998) pointed out an issue of using schedule information in an advanced and active manner. McKinney and Fischer (1998) highlighted the advanced use of graphic data as part of an automated scheduling process, and this effort may well illustrate the 'analysis' phase of BIM maturity.

'Morphology' indicates types of physical manipulation of BIM elements and/or databases. Traditional arrangements of database systems are 'distributed' or 'concentrated'. Extended concepts of this BIM 'morphology' were interestingly discussed by Tobin (2008) where he tested the effectiveness of "slice of BIM data" for" atomic BIM".

Finally, the 'implementation' variable strongly stresses the impact of managerial issues for successful BIM utilization. As previously discussed, 'strategy' and 'policy' direct all activities within an organization and hence characterize distinct requirements of information systems. 'Procedures' can be interpreted as construction business functions (e.g. value chain) 
that provide the most impacting basis for designing IS and BIM interfaces. A methodology prioritizing these business functions for construction companies were developed by Jung and Gibson (1999) in order to identify the most promising areas under different strategies and policies. Regardless of the degree of systemization or standardization, no information system can fully support the user to fill out the computerized procedures. In other words, details or decisions should be made before a user type in the lowest level data entry. Well organized 'manuals' reflecting distinct characteristics of an organization or a project (Jung and Kang 2007) facilitate smooth or automated operations.

\section{CONCLUSIONS}

CIC and BIM researches were reviewed and analyzed in this paper in order to address BIM variables for theory and implementation. A comprehensive BIM framework was then proposed based on these variables. This framework can provide a solid basis for 'evaluating promising areas' and 'identifying driving factors’ for practical BIM effectiveness.

It is inferred that researchers and practitioners in the construction industry have more focused on 'property' and 'standards' issues of BIM. More specifically, 'parametric' variable in 'property' category and 'product' variable in 'standards' category were most often discussed.

'Relation' issue are also well addressed exploring 'ontology' and 'reasoning' topics, but it is still in developing stage towards a higher 'maturity' phase. Researchers argue that this 'relation' can amplify advanced BIM implementation.

As a conclusion, 'utilization' research coupled with ontology and reasoning needs to be strongly encouraged in order to accelerate practical BIM implementation.

The authors of this paper believe that 'knowledge' (in 'level' variable) and 'reasoning' are the promising area for advanced BIM. Current research efforts by the authors are now attempting to embed these 'knowledge' and 'reasoning' into the 'geometric' objects. In order to secure the practicability, 'facet' and 'composition' are used as key tools based on 'implementation' 'perspectives'.

\section{ACKNOWLEDGEMENTS}

This study was supported by Korean Ministry of Education, Science, and Technology (MEST) under Grant No. 2009-0074881. The support is gratefully acknowledged.

\section{REFERENCES}

Bouchlaghem, D., Kimmance, A.G., and Anumba, C.J (2004) Integrating product and process information in the construction sector. Industrial Management \& Data Systems, 104(3), 2004, 218-233.

Caldas, C. H. and Soibelman, L (2003) Integration of Construction Documents in IFC Project Models. Construction Research Congress - Winds of Change: Integration and Innovation of Construction. 
Chinowsky, P. S. and Reinschmidt, K. F (1995) Qualitative Geometric Reasoner for Integrated Design. Journal of Computing in Civil Engineering, ASCE, 9(4), 250-258.

Cho, M. (2000) Development of Construction Project Management. Final research report to Korean Ministry of Science and Technology, Project: 98-NE-04-03-A, Seoul, Korea.

International Organization for Standardization (ISO). (1994). "Classification of information in the construction industry.” Technical Report 14177, Geneva, Switzerland.

Jung, Y. and Gibson, G. E (1998a) Data Sharing Effectiveness for Computer Integrated Construction. Journal of the Architectural Institute of Korea, 14(5), 371-377.

Jung, Y. and Gibson, G. E (1998b) Variation in CIC Driving Factors based upon Types of Construction Contracts. Proceedings of The Fifth International Conference on Automation Technology, Taipei, Taiwan, pp.199-.

Jung, Y. and Gibson, G. E (1999) Planning for Computer Integrated Construction. Journal of Computing in Civil Engineering, ASCE, 13(4), 217-225.

Jung, Y. and Kang, S (2007) Knowledge-Based Standard Progress Measurement for Integrated Cost and Schedule Performance Control. Journal of Construction Engineering and Management, ASCE, 133(1), 10-21.

Jung, Y., Kang, S., Kim, Y., and Park, C (2008) Assessment of Safety Management Information Systems for General Contractors. Safety Science, Elsevier, 46(4), 661-674.

Kim, H. and Grobler, F (2007) Building Ontology to Support Reasoning in Early Design. Proceeding of the 2007 ASCE International Workshop on Computing in Civil Engineering.

Koo, B. and Fischer, M (2000) Feasibility Study of 4D CAD in Commercial Construction. Journal of Construction Engineering and Management, 126(4), 251-260.

Kymmell, W (2008) Building Information Modelling - Planning and Managing Construction Projects with 4D CAD and Simulations. USA: McGraw-Hill books

MasterFormat. (2004). Construction Specifications Institute (CSI), Alexandria, Va.

McKinney, K. and Fischer, M (1998) Generating, evaluating and visualizing construction schedules with CAD tools. Automation in Construction, 7(6), 433-447.

Miyatake, Y. and Kangari, R (1993) Experiencing Computer Integrated Construction. Journal of Construction Engineering and Management, ASCE, 119(2), 307-322.

Sanvido, V. E. and Medeiros, D. J (1990) Applying Computer-Integrated Manufacturing Concepts to Construction. Journal of Construction Engineering and Management, ASCE, 116(2), 365-379.

Succar, B (2009) Building Information Modelling Framework: A Research and Delivery Foundation for Industry Stakeholders. Automation in Construction, 18(3), 357-375. 
Taylor, J. E. and Bernstein, P. G (2009) Paradigm Trajectories of Building Information Modeling Practice in Project Networks. Journal of Management in Engineering, ASCE, 25(2), 69-76.

Teicholz, P. and Fischer, M (1994) Strategy for Computer Integrated Construction Technology. Journal of Construction Engineering and Management, ASCE, 120(1), 117-131.

Tobin, J. (2008), "atomicBIM: Splitting Data to Unleash BIM’s Power”, available at: http://www.aecbytes.com/buildingthefuture/2008/atomicBIM.html”

Uniclass. (1997). Uniclass: Unified Classification for the Construction Industry. RIBA Publications: London. 